\title{
Determinants of Vietnam Government Bond Yield Volatility: A GARCH Approach*
}

\author{
Quoc Trung TRINH ${ }^{1}$, Anh Phong NGUYEN ${ }^{2}$, Hoang Anh NGUYEN ${ }^{3}$ Phu Thanh NGO ${ }^{4}$
}

Received: April 22, 2020 Revised: May 10, 2020 Accepted: June 07, 2020

\begin{abstract}
This empirical research aims to identify the relationship between fiscal and financial macroeconomic fundamentals and the volatility of government bonds' borrowing cost in an emerging country - Vietnam. The study covers the period from July 2006 to December 2019 and it is based on a sample of 1-year, 3-year, and 5-year government bonds, which represent short-term, medium-term and long-term sovereign bonds in Vietnam, respectively. The Generalized AutoRegressive Conditional Heteroskedasticity (GARCH) model and its derivatives such as EGARCH and TGARCH are applied on monthly dataset to examine and suggest a significant effect of fiscal and financial determinants of bond yield volatility. The findings of this study indicate that the variation of Vietnam government bond yields is in compliance with the theories of term structure of interest rate. The results also show that a proportion of the variation in the yields on Vietnam government bonds is attributed to the interest rate itself in the previous period, base rate, foreign interest rate, return of the stock market, fiscal deficit, public debt, and current account balance. Our results could be helpful in the macroeconomic policy formulation for policy-makers and in the investment practice for investors regarding the prediction of bond yield volatility.
\end{abstract}

Keywords : Emerging Markets, Vietnam Government Bonds, Bond Yield Volatility, Macroecomic Factors, GARCH

JEL Classification Code: E44, F21, F37, G18

\section{Introduction}

Both developed and developing economies draw enormous benefits of developing an effective and transparent

*This research is funded by Vietnam National University Ho Chi Minh City (VNU-HCM) under grant number C2018-34-02

${ }^{1}$ First Author. Associate Professor, University of Economics and Law, Ho Chi Minh City, Vietnam; Vietnam National University, Ho Chi Minh City, Vietnam; Email: tqtrung@uel.edu.vn

${ }^{2}$ Corresponding Author. Associate Professor, Faculty of Finance and Banking, University of Economics and Law, Ho Chi Minh City, Vietnam [Postal Address: 669 National Highway 1A, Quarter 3, Linh Xuan Ward, Thu Duc District, Ho Chi Minh City, 71309, Vietnam]. Email: phongna@uel.edu.vn

${ }^{3}$ Faculty of Finance and Banking, University of Economics and Law, Ho Chi Minh City, Vietnam; Vietnam National University, Ho Chi Minh City, Vietnam. Email: anhnh@uel.edu.vn

${ }^{4}$ Faculty of Finance and Banking, University of Economics and Law, Ho Chi Minh City, Vietnam; Vietnam National University, Ho Chi Minh City, Vietnam. Email: thanhnp@uel.edu.vn

(c) Copyright: The Author(s)

This is an Open Access article distributed under the terms of the Creative Commons Attribution Non-Commercial License (http://Creativecommons.org/licenses/by-nc/4.0/) which permits unrestricted noncommercial use, distribution, and reproduction in any medium, provided the original work is properly cited. government bond market. Yields on government bonds have drawn the attention of different types of economic entities. The government as the issuer is concerned with the bond yield since the yield refers to the cost to the government in the repurchase of bonds or the issuance of new bonds. Investors pay attention on bond yield and its volatility since the high-low yields reflect the return and the risk they face. Other economic players such as financial institutions or coporations keep an eye on government bond yields owing to the fact that they serve as a reference in determining prices of publishing corporate bonds and other financial products in the market.

For emerging countries like Vietnam, the 1997 Asian crisis and the 2008 financial crisis have awakened these countries' governments to the need to quickly develop other alternatives to bank credit and foreign currency debt as sources of funding. In this circumstance, the decision of developing a well-functioning bond market is a great choice. The Vietnam bond market is dominated by government bonds, followed by municipal and corporate bonds. The government bond market plays a key role in respect of meeting several important objectives: a capital mobilization 
channel for public investment projects, offsetting temporary deficit of the state budget, structuring the government debt, re-lending to the enterprises, financial institutions and local government.

In 2017, the Vietnamese government set out a road map ${ }^{1}$ to increase the bond market's size from about $20 \%$ (2015) to $45 \%$ and $60 \%$ of GDP by 2020 and 2030 , respectively. However, the problem is that governments with increasing deficit and above-average level of public debts will find that they have less financial flexibility (Vietnam ranks 70 out of 188 countries regarding public debt as a percentage of GDP). With the increase in public debt financing by issuing bonds, the question is whether Vietnam could reach the targets in the roadmap and how certain macroeconomic variables affect the government bond's borrowing cost. Besides, the variation of Vietnam government bond yields from 2006 to 2019 showed a slightly high level of instability. There are several periods in which Vietnam government bond yields were very high: the yield reached the highest level of $20.33 \%$ in June 2008 and more than $12 \%$ in the first three months of 2010 and the last six months of 2011. Meanwhile, the bond yield was at the lowest level of roughly $2 \%$ during the last three months of 2019. This situation and the lack of empirical studies on Vietnam government bond yields has become the driving force behind this research.

There is a large body of literature that highlights the determinants of government bond yields in advanced economies, with a majority of papers concentrating on the impact of fiscal policy and position on the bond yields. Most of these studies employ US, European and OECD data. Gale and Orszag (2003) report that, out of 59 studies, 29 find that weaker fiscal variables increase bond yields, while 11 have mixed results and 19 find that the effect is not significant. In addition, the effects of fiscal deficit and public debt on bond yield become much more obvious in single country studies than cross-country studies (Laubach, 2009). It is likely that the government bond yield in every single country is adjusted according to different government monetary policy and various economic conditions. There are also several studies conducted on government bond yields and the macroeconomic variables in emerging countries (Jaramillo \& Weber, 2013; Pham, 2014; Zaja, Jakovcevic \& Visic, 2018). However, while similar to studies in advanced countries, to date there has been little agreement on the impact of macroeconomic fundamentals on the bond yield. Other than that, most publications employed cross-country panel data rather than single country data. Therefore, this paper is designed to investigate determinants of government bond yield in a single emerging economy, Vietnam.

Our study contributes to the literature in several ways. First, while most of the previous studies focused on the developed markets by employing cross-country data (Giordano, Linciano \& Soccorso, 2012; Martinez, Terceno
\& Teruel, 2013; Poghosyan, 2014), this study takes a look at the bond market in a single emerging country, Vietnam, where there is very little research on the bond market relative to equity market. Second, acknowledging the importance of understanding the driving forces behind the time-variation of the bond return, this study examines the role of both shortterm and long-term domestic macroeconomic fundamentals in explaining variations in bond return. The macro factors in our empirical framework include public debt to GDP, fiscal deficit to GDP, current account to GDP, inflation rate, base (interest) rate, stock return, oil return rate, and foreign interest rate. In particular, in our study, the impact of the 2008 financial crisis is incorporated into the model by using a financial crisis dummy. Additionally, employing up-todate time series data allows us to address the timely issues that have now emerged as critical for investors and policymakers. Third, while the single-country studies typically employ OLS or fixed/random effect estimation (Dua \& Raje, 2014; Hsing, 2015; Giordano, Linciano \& Soccorso, 2012; Martinez, Terceno \& Teruel, 2013), our study explores the effect of macroeconomic factors on Vietnam government bond yield volatility by applying the GARCH framework. It is better to use GARCH models to describe financial markets in which volatility can be more important during periods of financial crises and less important during periods of relative calm and steady economic growth (Charles \& Darne, 2019).

The remainder of the paper is organized into five sections. Section 2 is devoted to a brief review of the related literature. In Section 3, we set out a brief description of the data and econometric approach. Section 4 presents the descriptive statistics and experimental results while the conclusion is reported in Section 5.

\section{Literature Review}

The research framework for this study applies the arbitrage pricing theory (APT) developed by Ross (1976). APT is a theory of asset pricing stating that a financial asset's return can be determined by common factors or macroeconomic factors and specific factors related to such assets. Based on the relationship between a security's expected return and its risks, the APT suggests a multi-factor pricing model for many studies that examine determinants of stock and bond's return (Alexopoulou, Bunda \& Ferrando, 2010; Gilles \& Leroy, 1991; Reschreiter, 2003). Gilles and Leroy (1991) confirm that government bond yield is highly affected by risks, including risks arising from the bond yield fluctuation or volatility risks and fundamental risks deriving from macroeconomic factors. In the same vein, Reschreiter (2003) employs the approach of APT in his research on the UK government bond yields and claimed that general factors affecting yields comprise financial variables and macroeconomic factors such as inflation, growth in 
retail sales and the stock market excess return. This study follows the approach outlined by APT, which focuses on macroeconomic fundamentals and volatility risk in the relationship with Vietnam government bond yields.

Though there is a rare chance that the government cannot meet its obligations to pay interest and principal of the bonds, the default risk of government bonds still exists. One of the factors that may increase the default risk is the budget deficit. Yet, the literature suggests that more government deficit may or may not lead to a higher bond yield. On the one hand, there is a concern that higher government deficit leads to an increase in the long-term financing costs and crowding out of the private investment since larger fiscal deficits could be considered less creditworthy. Many empirical results find a positive relationship between the budget deficit and government bond yields (Klose \& Weigert, 2014; Kameda, 2014; Gill, 2018). For instance, Klose and Weigert (2014) explicitly explore the role of budget variables in assessing the solvency of each country and confirm the positive relationship between budget deficits and government bond yields. By the same token, Kameda (2014) concedes that when budget deficit increases it will indirectly affect and raise the bond yields of the country. The author shows that in Japan, an increase of one percentage point in the deficit-toGDP ratio will raise the basis point by 26 . The recent study conducted by Gill (2018) reveals that coefficients of deficitto-GDP ratio, debt-to-GDP ratio and interest rate are positive in France, Italy, Spain, but negative in the UK and Greece. Meanwhile, Ardagna, Caselli and Lane (2007) with a panel of 16 OECD countries over 1960-2002, find that budget deficit and government bond yield are negative correlated. Gruber and Kamin (2012) argue that in the case governments are believed to be more creditworthy for several reasons such as their established record of timely repayment, the political stability and good performance of the economy, they will be charged lower financing costs. This, in turn, could result in the deficit expansion.

In addition to flow fiscal variable, the stock fiscal variable like public debt is also taken into consideration to investigate the impact on government bond yield. Much of the literature concede that, as government debt rises, sovereign bond yields should go up in recognition of the higher risk carried by investors holding government securities. Kinoshita (2006) employs a panel of 19 advanced economies and suggests that a 1-percentage point increase in the government debt-toGDP ratio raises the real government bond yield by about 2-5 basis points in the long run. This impact is comparable to the effect found in the study of Laubach (2009) for the U.S bond market and in Poghosyan (2014) for 22 advanced countries' data. Ardagna et al. (2007) also confirms the influence of public debt, with the effect of debt being more obvious for countries having above average debt levels. Jaramillo and Weber (2013) suggest that higher public debt increases bond yields in the emerging markets, where there is a large amount of uncertainty involved to the growth prospects of the economy. On the contrary, there are few scholars who find no correlation or even negative relationship between government debt and sovereign bond yields. For instance, in the study of sovereign bond yields in emerging Asia over the period 1994-2012, Pham (2014) claims that the bond yields are weakly and negatively correlated with the changes in public debt. Zaja et al. (2018), in the discussion of the relationship between fundamentals and bond market in the Republic of Croatia, report that in the pre-crisis period (2001Q3-2008Q2) and in the first period of the crisis (2008Q3-2012Q3), governmet debt in GDP shows a negative connection with bond yields and later (2012Q4-2017Q4) they are positively correlated. The authors conclude that the influence of public debt on bond yields are ambiguous and depend on other external factors.

Another factor that may help to explain the bond yield volatility is liquidity risk. The level of government liquidity is often measured by foreign exchange reserves. It has been suggested that the more foreign exchange reserves will lower the default risk of the government. When analyzing the economic determinants of creditworthiness indicators with the database of over 60 developing countries for the period 1980-1993, Haque, Mark and Mathieson (1998) report that the lower international reserves, the greater the threat of a sudden liquidity crisis and hence, the lower a country's risk rating. This, in turn, will lead to the higher borrowing costs of government debt. In line with this research, Diebold and Li (2006) examine the interaction between macroeconomic variables and US. Treasury yields over the period 1972-2000 and find the strong evidence of the effects of foreign exchange reserves on future movements in the yield curve.

Previous research also documents that variables representing the country's external competitiveness and ability to raise funds for debt servicing like current account balance could help to explain the variation of government bond yield (Giordano et al., 2012; Maltritz, 2012). If the balance of payments on the current account is positive, the creditworthiness indicator of the country will be expected to be higher. This will result in the decline in the government bond yield (Giordano et al., 2012). Conversely, current account deficits signal an increase in net public debt, which may impair the government's ability to meet its external payment obligations. In other words, the current account balance is associated negatively with the government bond yield. On the other side, Maltritz (2012) suggests that the relationship between the bond spreads and current account balance may be positive. The author argues that a positive current account surplus, which for the balance of payment identity is coupled with net capital outflows, might in fact signal either the inability of a country to borrow from abroad 
or a capital flight. As a result, the bond yield would increase and vice versa.

In addition, APT also proposes that financial markets are perfectly competitive and interconnected. Put another way, the change in the substitutionary and complementary markets such as the stock market and commodity markets could affect the price in the bond markets. There is a general understanding that stocks and government bonds are substitutes, so that an increase in the stock market return will result in a mitigation in government bond yields. Nevertheless, the literature so far reports heterogeneous results with respect to the stock-bond co-movement. The study by Alexopoulou et al. (2010) in Bulgaria, Hungary, Poland, and Slovakia supports the general belief by showing that the stock price index has negative effect on government bond yields. Meanwhile, Ilmanen (2003) demonstrates that stock market and government bond returns in the U.S was positive through most of the 1900s, but negative in the early 1930s, the late 1950s and in the 1990s. By the same token, using data from the US, UK and Germany, Andersson, Krylova and Vahamaa (2008) find that the stock-bond correlations in all three countries are positive most of the time, although sustained periods of negative correlation are also observed, esspecially during periods of modest inflation expectation. Lin, Yang, Marsh and Chen (2018) shows that the relations between stock and bond returns have positve sign in short time while the long-term stock-bond relation is significantly negative.

Besides, commodity markets are also supposed to have an association with the government bond market. Since the relationship between these markets might be complementary, a deterioration in commodity market performance will undermine sovereign bond yields and vice versa. In this study the performance of the commodities markets proxied with world oil prices. Studies conducted by Sun (1998) and Alexandre and Antonin (2010) also suggest a connection between the world oil price with government bonds yields.

As stated earlier, beside long-term macroeconomic fundamentals, in the short-run, government bond yields may be also affected by a number of variables. First of all, monetary policy can affect nominal interest rates through its impact on inflation expectations (Pham, 2014; Martinez et al., 2013). Furthermore, the inflation rate can be considered as a proxy for the quality of economic management. For that reason, the higher the inflation rate, the lower will be the creditworthiness rating. As indicated by the rich body of empirical studies on the negative relation between credit rating and borrowing cost (Haque et al., 1998; Han, Kang \& Shin, 2016) bonds with lower credit ratings yield more. This finding is supported by Baldacci, Gupta and Mati (2011), who argue that a high inflation could be resulted from the monetization of the fiscal deficit and imply the need for a higher interest rate. Likewise, several studies insist that the pricing of fixed income instruments is determined by the short-term domestic interest rate (Kalimipali \& Susmel, 2004; Gruber \& Kamin, 2012; Poghosyan, 2014). Gruber and Kamin (2012) confirm a positive correllation between the domestic interest rate levels and long term Treasury yields. Poghosyan (2014) also demonstrates that the changes in domestic interest rate which may lead to inflation shocks and changes in fiscal balances will have an impact on the short-run soveireign bond yield. In this study, we expect such a positive association between the domestic base rate and government bond yields. Other than that, we also include the variable of foreign interest rate as a measure of external shocks (proxied by U.S interest rate) to examine its relationship with the government bond yields in emerging country.

On the whole, the variation of government bond yields is affected by many fundamental factors, both long-term and short-term factors. Since the theoretical literature is inconclusive about the sign of the effect of those factors on the government bond yields, the question of its impact becomes an urgent for us to conduct the empirical study in an Asian emerging country like Vietnam.

\section{Research Methods and Materials}

\subsection{Data Setting}

Our empirical analysis employs a sample consisting of monthly data on macroeconomic fundamentals and Vietnam government bond which are denominated in VND and have fixed coupon rates, for the period from July 2006 to December 2019. In this study, the data comprise Vietnam government debt securities with a 1-year, 3-year and 5-year maturity range, that represent short-term, intermediate-term and longterm debt instruments, respectively. The government bond yields available in Bloomberg will be used as a measure of government borrowing costs. Data on macroeconomic fundamentals include government budget defictit, public debt, current account balance, foreign exchange reserves, inflation rate, world oil price, stock index, and base rate are obtained from reliable sources like Bloomberg, Reuters, ADB and World Bank.

\subsection{Model Specifications}

Much research on the determinants of government bond yields apply various regression analysis such as feasible generalized least-square estimator (Giordano et al., 2012), OLS (Radier et al., 2016; Zaja et al., 2018), and fixed or random effect model (Martinez et al., 2013). At the same time, several studies acknowledge the existence of volatility in government bond yields and a conditional heteroskedasticity in the covariance between stock returns and bond yields 
(Balli, 2009; De Goeij \& Marquering, 2004). Moreover, with asset returns, volatility seems to vary during certain periods of time, especially in the period of crisis (Schwert, 1989) and depend on past variance, making a homoskedastic model like OLS not optimal. Meanwhile, there is strong evidence that suggests that GARCH models with non-normal distributions are more robust in what comes to volatility forecasting than other historical models (Liu \& Morley, 2009). GARCH processes, being autoregressive, depend on past squared observations and past variances to model for current variance. GARCH processes are widely used in finance due to their effectiveness in modeling bond and stock returns (Engle, 2001; Sahadudheen, 2015; Tu \& Liao, 2020). Regarding bond returns, some panel data studies use GARCH models to capture the differences in the volatility of returns over time and found that government bond yields following the GARCH process (Balli, 2009; De Goeij \& Marquering, 2004).

However, GARCH cannot work well with the existence of leverage effects, volatility clusterings and leptokurtosis, which are often seen in financial returns data. Nelson (1991) proposes an EGARCH model that capture asymmetries in the volatility. Zakoian (1994) has evolved the conventional model into TGARCH to explore the asymmetric volatility arising in the risk-return relationship. This study aims to examine the impact of multi-macroeconomic factors on the yield volatility of Vietnam government bond with various terms to maturity under the influence of leverage as well as asymmetric effect in the time series data. Hence, we apply all three models of GARCH, EGARCH and TGARCH.

In addition, a visual representation of the variations of 1-year and 5-year government bond yields suggests that despite the difference in maturity, in general, the variation of these two bond yields shares similar features: high fluctuation in the crisis period and the volatility clusterings seems to be repeated cycle to cycle. Apart from that, the volatility of bond yields both circulate the value area of zero, which refers to a heteroskedasticity issue. This result proves that the application of GARCH, EGARCH and TGARCH models is reasonable (Figure 1 and 2)

The modeling process is as follows. First, we estimate the function of government bond yield using the following equation:

$$
r_{t}=\mu+\varepsilon_{t}
$$

In which $r_{t}$ denotes the government bond yield in month $\mathrm{t}$ (with different maturity, including 1-year government bond (GGVF1Y), 3-year government bond (GGVF3Y) and 5-year government bond (GGVF5Y)) ; $\mu$ is yield to maturity of bond and $\mathrm{t}$ is error term in the regression equation (1).
In order to estimate the volatility of government bond yields, our study employ three models of GARCH, EGARCH and TGARCH and incorporate macroeconomic fundamentals into the models

$\operatorname{GARCH}(1,1): \sigma_{t}^{2}=\alpha_{0}+\alpha_{1} \varepsilon_{t-1}^{2}+\beta_{1} \sigma_{t-1}^{2}+a_{1} C P I_{\mathrm{t}}+$ $a_{2}$ FER $_{\mathrm{t}}+a_{3}$ Baserate $_{\mathrm{t}}+a_{4}$ Oilrate $_{\mathrm{t}}+a_{5}$ FIR $_{\mathrm{t}}+a_{6}$ Stockreturn $_{\mathrm{t}}$ $+a_{7}$ Fiscal $_{\mathrm{t}}+a_{8}$ Pubdeb $_{\mathrm{t}}+a_{9}$ CurrentAcc $_{\mathrm{t}}$

$\operatorname{TGARCH}(1,1): \sigma_{t}^{2}=\alpha_{0}+\alpha_{1} \varepsilon_{t-1}^{2}+\beta_{1} \sigma_{t-1}^{2}+\gamma \varepsilon_{t-1}^{2} I_{t-1}$ $+b_{1} C P I_{\mathrm{t}}+b_{2}$ FER $_{\mathrm{t}}+b_{3}$ Baserate $_{\mathrm{t}}+b_{4}$ Oilrate $_{\mathrm{t}}+b_{5}$ FIR $_{\mathrm{t}}+$ $b_{6}$ Stockreturn $_{\mathrm{t}}+b_{7}$ Fiscal $_{\mathrm{t}}+b_{8}$ Pubdeb $_{\mathrm{t}}+b_{9}$ CurrentAcc $_{\mathrm{t}}$ (3)

$\operatorname{EGARCH}(1,1): \quad \ln \sigma_{t}^{2}=\alpha_{0}+\alpha_{1}\left|\frac{\varepsilon_{t-1}}{\sigma_{t-1}}\right|+\gamma \frac{\varepsilon_{t-1}}{\sigma_{t-1}}+$ $\beta_{1} \ln _{t-1}^{2}+c_{1} C P I_{\mathrm{t}}+c_{2}$ FER $_{\mathrm{t}}+c_{3}$ Baserate $_{\mathrm{t}}+c_{4}$ Oilrate $_{\mathrm{t}}+c_{5}$ FIR $_{\mathrm{t}}$ $+c_{6}$ Stockreturn $_{\mathrm{t}}+c_{7}$ Fiscal $_{\mathrm{t}}+c_{8}$ Pubdeb $_{\mathrm{t}}+c_{9}$ CurrentAcc $_{\mathrm{t}}(4)$

Where: $\sigma_{t}^{2}$ is the variance of government bond yield in month $\mathrm{t}$

$\varepsilon_{t-1}^{2}$ is mean square error in the regression equation (1);

$\sigma_{t-1}^{2}$ is the variance of government bond yield in the previous month (t-1);

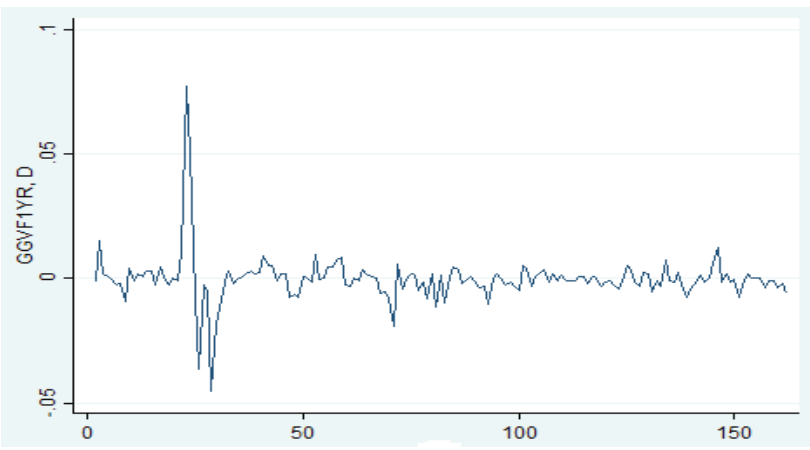

Figure 1: The Volatility of 1-Year Government Bond Yield

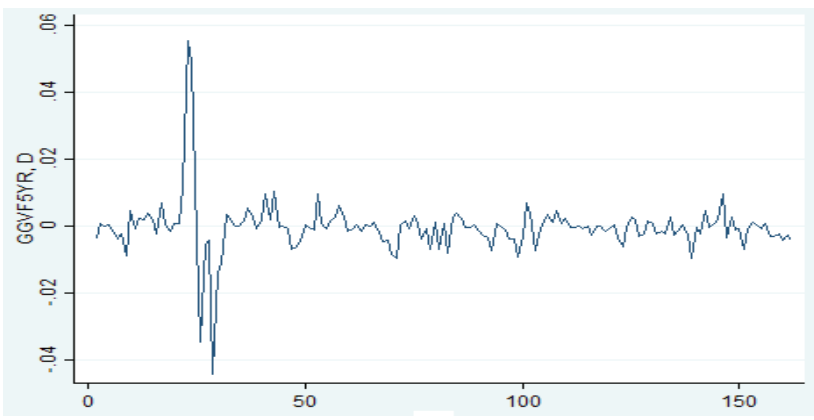

Figure 2: The Volatility of 5-Year Government Bond Yield 
$I_{t-1}$ is a binary variable that split the observations into two sub-clusters - crisis period takes the value of 1 and noncrisis period takes the value of 0 ;

$\alpha_{0}$ is constant;

$\alpha_{1}, \beta_{1}, \gamma, \mathrm{a}_{1}, \mathrm{~b}_{1}, \mathrm{c}_{1}, \ldots, \mathrm{a}_{9}, \mathrm{~b}_{9}, \mathrm{c}_{9}$ are slope coefficients of respective predictors;

$\mathrm{CPI}_{\mathrm{t}}$ is the inflation rate in month $\mathrm{t}$;

$\mathrm{FER}_{\mathrm{t}}$ is non-gold monthly foreign exchange reserves (in USD) in month $\mathrm{t}$;

Baserate $_{t}$ is the base rate of Vietnam in month $t$;

Oilrate is the world oi return in month $t$;

$\mathrm{FIR}_{t}$, is the foreign interest rate (US interest rate) in month $\mathrm{t}$;

Stockreturn $_{t}$ is the return of VN-Index in month t;

Fiscal $_{t}$ is overall budget surplus or deficit as a percentage of GDP in month $t$

Pubdeb $_{t}$ is general government debt as a percentage of GDP in month $\mathrm{t}$;

CurrentAcc $\mathrm{A}_{\mathrm{t}}$ is current account balance as a percentage of GDP in month $t$;

\section{Results and Discussion}

\subsection{Descriptive Statistics}

Table 1 describes the sample data collected from July 2006 to December 2019 with a total of 162 observations.

The time series is separated into two subsets to capture the volatility of bond yield under the impact of extreme event: the crisis period from 2008-2009 and the non-crisis period. The data shows that the average value of bond yields increase

Table 1: Descriptive Statistics of Variables

\begin{tabular}{|l|c|c|c|c|c|}
\hline \multicolumn{1}{|c|}{ Variables } & Obs & Mean & $\begin{array}{c}\text { Std. } \\
\text { Dev }\end{array}$ & Min & Max \\
\hline GGVF1Y & 162 & 0.071 & 0.036 & 0.015 & 0.211 \\
\hline GGVF3Y & 162 & 0.076 & 0.034 & 0.018 & 0.206 \\
\hline GGVF5Y & 162 & 0.080 & 0.033 & 0.02 & 0.203 \\
\hline CPI (\%) & 162 & 0.601 & 0.793 & -0.756 & 3.912 \\
\hline FER (bil. \$) & 162 & 31,13 & 1,63 & 11,25 & 68,81 \\
\hline Baserate (\%) & 162 & 8.89 & 1.08 & 7.00 & 14.00 \\
\hline Oilrate (\%) & 162 & 0.31 & 9.15 & -32.62 & 29.71 \\
\hline FIR (\%) & 162 & 1.48 & 1.83 & 0.31 & 9.00 \\
\hline Stockreturn (\%) & 162 & 0.76 & 8.80 & -24.01 & 38.51 \\
\hline Fiscal (\%) & 162 & -2.87 & 1.86 & -5.03 & 1.22 \\
\hline Pubdebt (\%) & 162 & 50.43 & 6.87 & 38.4 & 59.66 \\
\hline CurrentAcc (\%) & 162 & -0.39 & 5.18 & -11.00 & 6.00 \\
\hline
\end{tabular}

in accordance with term to maturity, whereby the average yield of 1 -year bonds is $7.14 \%$, 3-year bonds is $7.69 \%$, and 5 -year bonds is $8.08 \%$. This is in line with the theory stating that bonds with longer maturities tend to offer higher yields. However, regardless of the theory that long-maturity bonds are more sensitive to rate changes than short-maturity ones, the standard deviations that represent the volatility of bond yields reverse the tendency: 1-year bonds witness the highest variation $(3.62 \%)$ while 3 -year and 5 -year bonds show the variation of $3.45 \%$ and $3.31 \%$, respectively.

The application of GARCH models on time series data requires a statistical stationarity of data. Therefore, we apply the Augmented Dickey-Fuller (ADF) test to identify stationary series. The ADF test result shows that there are several non-stationary variables, which need to take differencing to become stationary (GGVF1Y, GGVF3Y, GGVF5Y, FER, Pubdebt and CurrentAcc). These differentiating variables are employed in the models of GARCH, TGARCH and EGARCH.

\subsection{Estimation Results}

Table 2 reports the estimation findings of multifactor GARCH, TGARCH and EGARCH models in which all key fundamental variables are added.

The estimation results of model 1 indicate that, on average, the bond yields in various maturity terms are negative and statistically significant. As seen from Table 1, the government bond yield experienced a gradual decrease over the research period and the variation of long-term bond yield is higher than short-term bond yield over time. In particular, the difference between the yield in this period and that in the previous period rises conforming to the longer maturity term - for the 1-year, 3 -year and 5 -year government bond is $-0.029 \%,-0.039 \%$ and $-0.041 \%$, respectively. These results are compatible with the concepts of the term structure of interest rate, which refers to the relationship between the yields and maturity structure of a set of bonds. The longer the time period involved, the greater the uncertainty; therefore, investors will require a higher yield to compensate them for the increased risk.

Considering the results of model 2, which employs GARCH $(1,1)$ aproach, the coefficient $\alpha_{1}$ is only statistically significant in the case of 1 -year government bond. This finding implies that investors in Vietnam are more interested in short-term government bonds for the purpose of enhancing liquidity than in long-term ones. Besides, the coefficients of $\beta_{1}$ are statistically significant, suggesting that the yield variation (or risk) in the previous period has a strong impact on the current yield variation (or risk). As could be expected, the total value of $\left(\alpha_{1}+\beta_{1}\right)<1$ indicates that the shock effect diminishes gradually in the post-crisis period and this effect does not persist in the long run but exist in short-term extreme period. 
Table 2: Estimation Outputs of Multifactor GARCH, TGARCH and EGARCH Models

\begin{tabular}{|c|c|c|c|c|c|c|c|c|c|}
\hline \multirow{2}{*}{ Coefficients } & \multicolumn{3}{|c|}{$\operatorname{GARCH}(1,1)$} & \multicolumn{3}{|c|}{ T-GARCH $(1,1)$} & \multicolumn{3}{|c|}{ E-GARCH $(1,1)$} \\
\hline & GGVF1Y & GGVF3Y & GGVF5Y & GGVF1Y & GGVF3Y & GGVF5Y & GGVF1Y & GGVF3Y & GGVF5Y \\
\hline $\begin{array}{l}\text { Return } \\
\text { (Model 1) }\end{array}$ & $\begin{array}{c}-0.00029 \\
\left({ }^{*}\right)\end{array}$ & $\begin{array}{c}-0.00039 \\
\left({ }^{*}\right)\end{array}$ & $\begin{array}{c}-0.00041 \\
\left({ }^{*}\right)\end{array}$ & $\begin{array}{c}-0.00029 \\
\left({ }^{*}\right)\end{array}$ & $\begin{array}{c}-0.00039 \\
\left({ }^{*}\right)\end{array}$ & $\begin{array}{c}-0.00041 \\
\left({ }^{*}\right)\end{array}$ & $\begin{array}{c}-0.00029 \\
\left({ }^{*}\right)\end{array}$ & $\begin{array}{c}-0.00039 \\
\left({ }^{*}\right)\end{array}$ & $\begin{array}{c}-0.00041 \\
\left({ }^{*}\right)\end{array}$ \\
\hline \multicolumn{10}{|l|}{ Risk (Model 2) } \\
\hline$\alpha_{0}$ & 0.00007 & $\begin{array}{c}-0.00127 \\
\left({ }^{* *}\right)\end{array}$ & $-\frac{0.00086}{\left.{ }^{* * \star}\right)}$ & & & & & & \\
\hline$\alpha_{1}$ & $\begin{array}{c}-0.0746 \\
\left(^{*}\right)\end{array}$ & -0.0227 & -0.0187 & & & & & & \\
\hline$\beta_{1}$ & $\begin{array}{c}0.5178 \\
\left(^{*}\right)\end{array}$ & $\begin{array}{c}0.3967 \\
\left(^{*}\right)\end{array}$ & $\begin{array}{c}0.4642 \\
\left(^{*}\right)\end{array}$ & & & & & & \\
\hline$\alpha_{1}+\beta_{1}$ & 0.4432 & 0.3740 & 0.4456 & & & & & & \\
\hline$a_{1}$ & 0.0001 & 0.00001 & 0.0000 & & & & & & \\
\hline$a_{2}$ & $\begin{array}{c}-0.0005 \\
(* *)\end{array}$ & 0.00023 & 0.0001 & & & & & & \\
\hline$a_{3}$ & $\begin{array}{c}0.0016 \\
\left({ }^{*}\right)\end{array}$ & $\begin{array}{c}0.00128 \\
\left(^{*}\right)\end{array}$ & $\begin{array}{c}0.0010 \\
\left({ }^{*}\right)\end{array}$ & & & & & & \\
\hline$a_{4}$ & 0.00001 & $\begin{array}{c}0.00002 \\
\left({ }^{* *}\right)\end{array}$ & $\begin{array}{c}0.00008 \\
\left({ }^{* * *}\right)\end{array}$ & & & & & & \\
\hline$a_{5}$ & 0.00001 & $\begin{array}{c}-0.00021 \\
\left({ }^{* *}\right)\end{array}$ & $\begin{array}{c}-0.00015 \\
\left({ }^{* *}\right)\end{array}$ & & & & & & \\
\hline$a_{6}$ & 0.00001 & $\begin{array}{c}0.00002 \\
\left({ }^{* * *}\right)\end{array}$ & $\begin{array}{c}0.00001 \\
\left({ }^{* * *}\right)\end{array}$ & & & & & & \\
\hline$a_{7}$ & $\begin{array}{c}-0.0041 \\
\left({ }^{*}\right)\end{array}$ & $\begin{array}{c}-0.00025 \\
\left(^{*}\right)\end{array}$ & $\begin{array}{c}-0.00021 \\
\left({ }^{* *}\right)\end{array}$ & & & & & & \\
\hline$a_{8}$ & $\begin{array}{c}-0.00006 \\
\left({ }^{*}\right)\end{array}$ & $\begin{array}{c}-0.00008 \\
\left({ }^{*}\right)\end{array}$ & $\begin{array}{c}-0.00006 \\
\left(^{*}\right)\end{array}$ & & & & & & \\
\hline$a_{9}$ & $\begin{array}{c}-0.00014 \\
\left({ }^{*}\right)\end{array}$ & $\begin{array}{c}-0.00014 \\
\left({ }^{*}\right)\end{array}$ & $\begin{array}{c}-0.00011 \\
\left({ }^{*}\right)\end{array}$ & & & & & & \\
\hline \multicolumn{10}{|l|}{ Risk (Model 3) } \\
\hline$\alpha_{0}$ & & & & 0.00052 & $\begin{array}{c}-0.01313 \\
\left({ }^{* *}\right)\end{array}$ & -0.0075 & & & \\
\hline$\alpha_{1}$ & & & & 0.05157 & 0.1621 & -0.0181 & & & \\
\hline$\beta_{1}$ & & & & $\begin{array}{c}0.51918 \\
\left(^{*}\right)\end{array}$ & $\begin{array}{c}0.3935 \\
\left({ }^{*}\right)\end{array}$ & $\begin{array}{c}0.4725 \\
(*)\end{array}$ & & & \\
\hline$Y$ & & & & -0.1277 & -0.1865 & 0.0289 & & & \\
\hline$\alpha_{1}+\beta_{1}$ & & & & 0.5708 & 0.5556 & 0.4545 & & & \\
\hline$b_{1}$ & & & & 0.00006 & 0.0000 & 0.00001 & & & \\
\hline$b_{2}$ & & & & $\begin{array}{c}-0.00052 \\
\left({ }^{* *}\right)\end{array}$ & 0.00023 & 0.00008 & & & \\
\hline$b_{3}$ & & & & $\begin{array}{c}0.00159 \\
\left(^{*}\right)\end{array}$ & $\begin{array}{c}0.00129 \\
\left(^{*}\right)\end{array}$ & $\begin{array}{c}0.00093 \\
\left(^{*}\right)\end{array}$ & & & \\
\hline $\mathrm{b}_{4}$ & & & & 0.00001 & $\begin{array}{c}0.00002 \\
\left({ }^{* *}\right)\end{array}$ & $\begin{array}{c}0.00001 \\
\left({ }^{* \star *}\right)\end{array}$ & & & \\
\hline
\end{tabular}




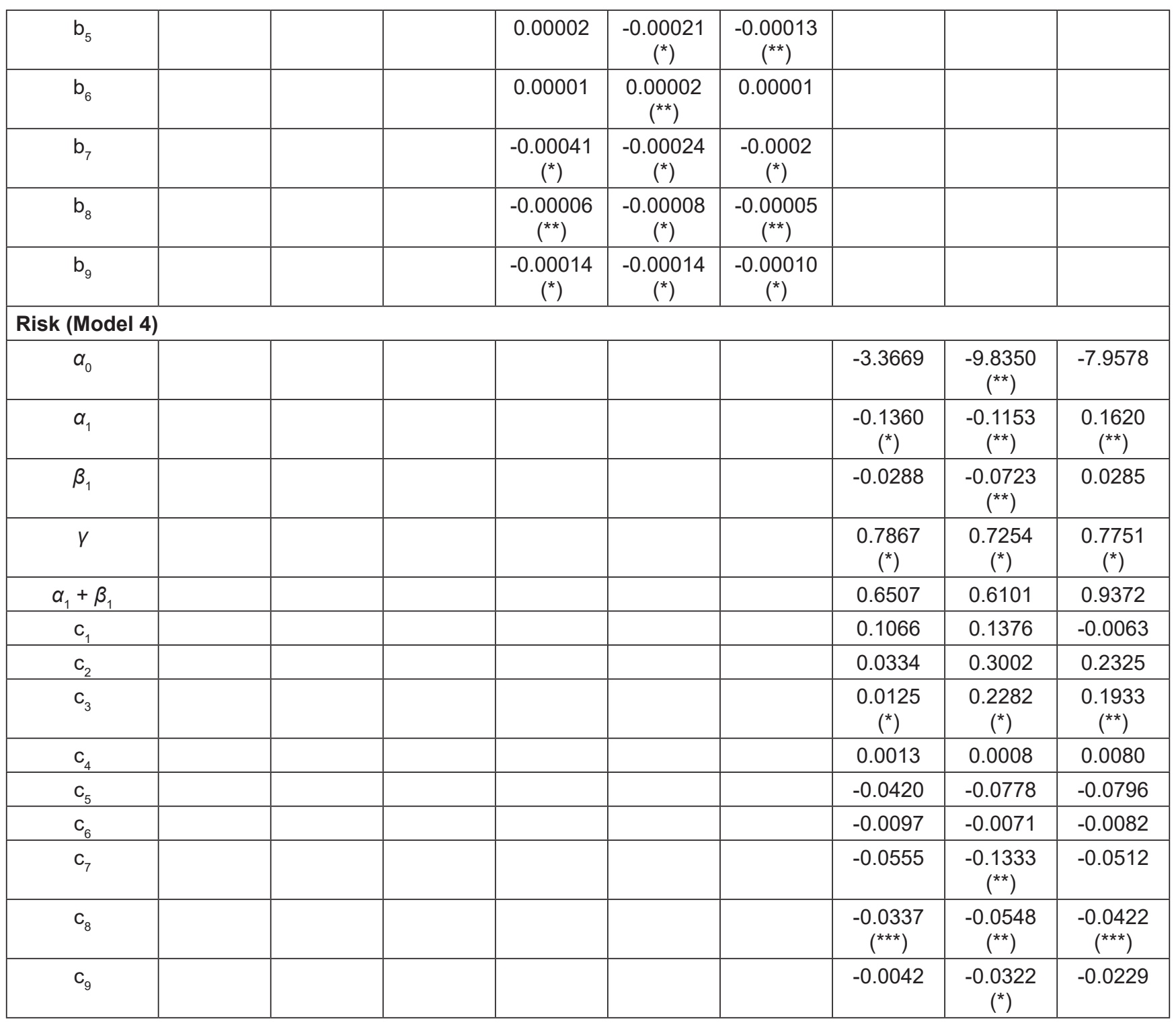

Note: $\left({ }^{*}\right) p<0.01 ;\left({ }^{* *}\right) p<0.05 ;\left({ }^{* * *}\right) p<0.1$

Considering the results of model 2, which employs $\operatorname{GARCH}(1,1)$ aproach, the coefficient $\alpha_{1}$ is only statistically significant in the case of 1-year government bond. This finding implies that investors in Vietnam are more interested in short-term government bonds for the purpose of enhancing liquidity than in long-term ones. Besides, the coefficients of $\beta_{1}$ are statistically significant, suggesting that the yield variation (or risk) in the previous period has a strong impact on the current yield variation (or risk). As could be expected, the total value of $\left(\alpha_{1}+\beta_{1}\right)<1$ indicates that the shock effect diminishes gradually in the post-crisis period and this effect does not persist in the long run but exist in short-term extreme period.
Lastly, contrary to expectations as well as earlier empirical studies, stock and flow fiscal-related variables such as fiscal deficit (Fiscal), public debt (Pubdebt) and current account banlance (CurrentAcc) have significantly negative effect on the goverment bond yield volatility at all maturity terms. This result does not support the consideration of scholars like Ardagana et al. (2007), Giordano et al. (2012), Kameda (2014), or Kinoshita (2006) who argue that rising government debt, budget deficit and current account deficit may foster sovereign bond yields through the default risk premium. There are several possibe explanations for the negative but pretty small relationship between public debt, budget deficit, current account balance and government 
bond yield volatility in Vietnam. First, since the financial crisis 2008, Vietnam has experienced a number of supportive factors including gradual fiscal consolidation, strict limits on government guarantees, financial repression that keep interest rates low during the past decade (Nguyen, 2019). Second, the public debt ratio of Vietnam has still remained at manageable levels and not yet exceeded the debt ceiling allowed by the government. Third, it may be the case that the political stability and robust economic growth during the past decade have contributed to enhance Vietnam's creditworthiness, which in turn leads to lower borrowing costs. Nevertheless, this finding is in agreement with several studies that show that fiscal position and government bond yield are negative associated (Gruber \& Kamin, 2012; Pham, 2014, Zaja et al., 2018).

The results of TGARCH model are quite comparable with the findings of GARCH with regards to almost all explanatory variables. The only difference between these two models is coefficient which stands for the leverage effect though it is statistically insignificant, that is to say good or bad information has little effect on bond risk.

At last, for the EGARCH model, though the previous period's volatility shows a strong influence on the current bond yield volatility, the value $\left(\alpha_{1}+\beta_{1}\right)$ is less than 1 , which refers to the short-term decreasing shock effect in volatility models.

The asymmetric effect at the coefficient $\gamma$ in the model has value less than 0 and is statistically significant in respect of only medium-term bonds. The results imply that there exists the impact of return shocks and subsequent shocks to medium-term bond yield volatility - if a larger shock increases the value of variance, this will lead to an increase in medium-term bond risk in the next period. The results of EGARCH are quite different from GARCH and TGARCH except for public debt ratio and interest rate variables, most of other fundamental variables are statistically insignificant. The variables of public debt ratio and current account balance have a significantly negative impact on only medium term bonds.

\section{Conclusions}

In recent years, Vietnam bond market has developed rapidly, contributing to the mobilization of resources for the government, provincial governments, policy banks, and corporations. Among bond instruments, Vietnam government bonds as a dominant issuer have drawn interest from both foreign and domestic investors. Government bonds have become a hedging instrument to ensure liquidity for institutions and investment funds. Hence, the investigation of factors that have an impact on the yield volatility of bonds at various maturity terms make a significant contribution to the investment practice. Additionally, our findings might be also useful in macroeconomic policy formulation, since understanding the dynamics of determinants of bond yield volatility is important for modeling and forecasting longterm interest rates.

The above estimated results indicate that the variation of government bond yield is in compliance with the theories of term structure and risk-return tradeoff that confirm longerterm bonds have higher yields than short-term ones. The findings from all three models of GARCH, TGARCH and EGARCH show the impact of the bond yield volatility in the previous period on the current period. This might be a signal for investors in the prediction of bond yield volatility. On the other side, information and leverage effect does not substantially affect the bond yield volatility, that is to say, shocks have a short-run impact on medium-term bonds.

Furthermore, this research confirms previous findings and contributes to our understanding of the impact of domestic and global macroeconomic fundamentals on time variations in the bond yield in a developing country like Vietnam. Specifically, of the complete set macroeconomic factors examined, the basic interest rate, world oil return, foreign interest rate, stock return, fiscal deficit, public debt and current account balance are identified as the statistically significant variables affecting the volatility of bond yield, meanwhile no evidence of the relationship between inflation rate and bond risk is detected. Besides, the coefficient the $\gamma$ in the TGARCH and EGARCH models is almost statistically insignificant; hence, it is more reasonable to predict the variation of bond yield by employing GARCH with the incorporation of macro variables.

\section{References}

Alexandre, H., \& Antonin, B. D. (2010). Oil prices and government bond risk premiums. Lahore Journal of Business, 1(1), 1-21.

Alexopoulou, I., Bunda, I., \& Ferrando, A. (2010). Determinants of government bond spreads in new EU countries. Eastern European Economics, 48(5), 5-37.

Andersson, M., Krylova, E., \& Vahamaa, S. (2008). Why does the correlation between stock and bond returns vary over time? Applied Financial Economics, 18(2), 139-151.

Ardagna, S., Caselli, F., \& Lane, T. (2007). Fiscal discipline and the cost of public debt service: some estimates for OECD countries. The BE Journal of Macroeconomics, 7(1). https:// doi.org/10.2202/1935-1690.1417

Baldacci, E., Gupta, S., \& Mati, A. (2011). Political and fiscal risk determinants of sovereign spreads in emerging markets. Review of Development Economics, 15(2), 251-263.

Balli, F. (2009). Spillover effects on government bond yields in euro zone. Does full financial integration exist in European government bond markets? Journal of Economics and Finance, 33(4), 331-363. 
Charles, A., \& Darne, O. (2019). The accuracy of asymmetric GARCH model estimation. International Economics, 157, 179202.

De Goeij, P., \& Marquering, W. (2004). Modeling the conditional covariance between stock and bond returns: A multivariate GARCH approach. Journal of Financial Econometrics, 2(4), 531-564.

Diebold, F. X., \& Li, C. (2006). Forecasting the term structure of government bond yields. Journal of Econometrics, 130(2), 337-364.

Dua, P., \& Raje, N. (2014). Determinants of yields on government securities in India. Margin: The Journal of Applied Economic Research, 8(4), 375-400.

Engle, R. (2001). GARCH 101: The use of $\mathrm{ARCH} / \mathrm{GARCH}$ models in applied econometrics. Journal of Economic Perspectives, 15(4), 157-168.

Gale, W. G., \& Orszag, P. R. (2003). Economic effects of sustained budget deficits. National Tax Journal, 6(3), 463-485.

Gill, N. (2018). A research on eurozone bond market and determinants of sovereign bond yields. Journal of Financial Risk Management, 7(2), 174-190.

Gilles, C., \& LeRoy, S. F. (1991). On the arbitrage pricing theory. Economic Theory, 1(3), 213-229.

Giordano, L., Linciano, N., \& Soccorso, P. (2012). The determinants of government yield spreads in the Euro Area. CONSOB Working Papers No. 71. Retrieved from: http://dx.doi. org/10.2139/ssrn.2158709

Gruber, J. W., \& Kamin, S. B. (2012). Fiscal positions and government bond yields in OECD countries. Journal of Money, Credit and Banking, 44(8), 1563-1587.

Haque N. U., Mark N.C., \& Mathieson, D. J. (1998). The relative importance of political and economic variables in creditworthiness ratings. IMF Working Paper. Retrieved from IMF website: https://www.imf.org/external/pubs/ft/wp/ wp9846.pdf

Han, S. H., Kang, K., \& Shin, Y. S. (2016). Bond ratings, corporate governance, and cost of debt: The case of Korea. Journal of Asian Finance, Economics and Business, 3(3), 5-15. https:// doi.org/10.13106/jafeb.2016.vol3.no3.5.

Hsing, Y. (2015). Determinants of the government bond yield in Spain: a loanable funds model. International Journal of Financial Studies, 3(3), 342-350.

Ilmanen, A. (2003). Stock-bond correlations. The Journal of Fixed Income, 13(2), 55-66.

Jaramillo, L., \& Weber, A. (2013). Bond yields in emerging economies: it matters what state you are in. Emerging Markets Review, 17, 169-185.

Kalimipali, M., \& Susmel, R. (2004). Regime-Switching Stochastic Volatility and Short-term Interest Rates. Journal of Empirical Finance, 11(3), 309-329.

Kameda, K. (2014). Budget deficits, government debt, and longterm interest rates in Japan. Journal of the Japanese and International Economies, 32, 105-124.
Kinoshita, N. (2006). Government debt and long-term interest rates (No. 2006-2063). International Monetary Fund.

Klose, J., \& Weigert, B. (2014). Sovereign yield spreads during the euro crisis: Fundamental factors versus redenomination risk. International Finance, 17(1), 25-50.

Laubach, T. (2009). New evidence on the interest rate effects of budget deficits and debt. Journal of the European Economic Association, 7(4), 858-885.

Lin, F.L., Yang, S.Y., Marsh, T., \& Chen, Y.F. (2018). Stock and bond return relations and stock market uncertainty: Evidence from wavelet analysis. International Review of Economics \& Finance, 55, 285-294.

Liu, W., \& Morley, B. (2009). Volatility forecasting in the hang seng index using the GARCH approach. Asia-Pacific Financial Markets, 16(1), 51-63.

Maltritz, D. (2012). Determinants of sovereign yield spreads in the Eurozone: A Bayesian approach. Journal of International Money and Finance, 31(3), 657-672.

Martinez, L. B., Terceno, A., \& Teruel, M. (2013). Sovereign bond spreads determinants in Latin American countries: Before and during the XXI financial crisis. Emerging Markets Review, 17, 60-75.

Nelson, D. B. (1991). Conditional heteroskedasticity in asset returns: A new approach. Econometrica: Journal of the Econometric Society, 59(2), 347-370.

Nguyen, H. H. (2019). The Role of State Budget Expenditure on Economic Growth: Empirical Study in Vietnam. Journal of Asian Finance, Economics and Business, 6(3), 81-89. https:// doi.org/10.13106/jafeb.2019.vol6.no3.81

Pham, T. H. H. (2014). Sovereign bond yields in emerging Asia: New evidence. Working paper, HAL. Retrieved from HAL website: https://hal.archives-ouvertes.fr/hal-01012093/document

Poghosyan, T. (2014). Long-run and short-run determinants of sovereign bond yields in advanced economies. Economic Systems, 38(1), 100-114.

Radier, G., Majoni, A., Njanike, K., \& Kwaramba, M. (2016). Determinants of bond yield spread changes in South Africa. African Review of Economics and Finance, 8(2), 50-81.

Reschreiter, A. (2003). Risk factors of inflation-indexed and conventional government bonds and the APT. Proceedings of the Money, Macro and Finance (MMF) Conference, University of Cambridge, UK, July, 2003.

Ross, Stephen A. (1976). The arbitrage theory of capital asset pricing. Journal of Economic Theory 13, 341-360.

Sahadudheen, I. (2015). An Exponential GARCH Approach to the Effect of Impulsiveness of Euro on Indian Stock Market. Journal of Asian Finance, Economics and Business, 2(3), 17-22. https://doi.org/10.13106/jafeb.2015.vol2.no3.17

Schwert, G. W. (1989). Why does stock market volatility change over time? Journal of finance, 44(5), 1115-1153. 
Sun, J. (1998). Changes in energy consumption and energy intensity: a complete decomposition model. Energy economics, 20(1), 85- 100 .

Tu, T. T., \& Liao, C. W. (2020). Block Trading Based Volatility Forecasting: An Application of VACD-FIGARCH Model. Journal of Asian Finance, Economics and Business, 7(4), 59-70. https://doi.org/10.13106/jafeb.2020.vol7.no4.59

Zaja, M. M., Jakovcevic, D., \& Visic, L. (2018). Determinants of the government bond yield: Evidence from a highly euroised small open economy. Proceedings of the 8th Business \& Management Conference, Venice, January, 2018
Zakoian, J. M. (1994). Threshold heteroskedastic models. Journal of Economic Dynamics and Control, 18(5), 931-955.

\section{Endnotes:}

The Roadmap for Developing the Bond Market, 2017-2020 and Vision Toward 2030 was formally adopted in Decision No. 1191/QĐ-TTg in August 2017. Retrieved from: http://www. vbma.org.vn/vbma/news/detail.do? category $=11 \& \mathrm{id}=947$ 